\title{
1984 年度国産乗用車のオクタン価要求值調査結果
}

\author{
石油学会製品部会ガソリン分科会オクタン価要求值専門委員会
}

(昭和 60 年 5 月 28 日受理)

\begin{abstract}
本調査は 1984 年型国産乗用車のオクタン価要求值分布を把握することを目的とし, 石油連盟の依頼により実施さ れた。試験は JPI-6S-6-84 に準拠し, 低速法でのオクタン価要求值分布を正標準然料および全沸点型標準然料（混 合系) の計 2 種で, 試験車 12 車種 111 台を対象に実施した。統計処理は’83 年度の調査結果のらち仕様変更なく引 続き販売されている 12 車種 97 台の結果を加えて行った。その結果, 正標準然料における低速法オクタン価要求值 分布は 50 および 90\% 充足率でそれぞれ 89.6 および 94.1 オクタンであった。これは前年度に比べ 50 および 90\% 充足率で 0.3 0.9 オクタン低い值になっている。
\end{abstract}

\section{1. 緒言}

本調査は石油業界として，自動車のオクタン価要求值に見合 ったオクタン価のガソリンを供給する必要から，毎年市場に出 る新型乗用車を対象にオクタン価要求值を調査し, 適正なオク タン価を把握する資料とすることを目的に，昭和 34 年度より
石油連盟の 委託事業として 開始し，本年度で 26 回目を迎え た。

この間, 自動車をとりまく情勢も年々変化し, 最近ではェレ クトロニクス応用の拡大や FF 車の增加, さらにはターボチャ ージャ付き車の扗大やエンジンの高圧縮比化等省然費, 高性能 エンジンへの指向が進んでいる。また, 本年度は自動変速機付

Table 1 Test Vehicle and Engine Types

\begin{tabular}{|c|c|c|c|c|}
\hline Vehicle & Engine Type & $\begin{array}{r}\mathrm{Nu} \\
1984\end{array}$ & $\begin{array}{l}\text { of Car } \\
1983\end{array}$ & $\begin{array}{l}\text { Tested } \\
\text { Total }\end{array}$ \\
\hline $\begin{array}{l}\text { Cedric } \\
\text { Gloria } \\
\text { Laurel } \\
\text { Silvia }\end{array}$ & $\begin{array}{l}\text { VG20E } \\
\text { VG20E } \\
\text { CA18S } \\
\text { FJ20ET, CA18ET, CA18S }\end{array}$ & 9 & 7 & 16 \\
\hline Skyline & GA18S, GA18E & 9 & 5 & 14 \\
\hline Bluebird & CA18, CA18E, CA18ET & 8 & 6 & 14 \\
\hline $\begin{array}{l}\text { Stanza } \\
\text { Liberta } \\
\text { Sunny } \\
\text { Pulsar }\end{array}$ & $\begin{array}{l}\text { CA16 } \\
\text { E15 } \\
\text { E15S, E15ET, E13S } \\
\text { E13S }\end{array}$ & 11 & 9 & 20 \\
\hline March & MA10S & 8 & 9 & 17 \\
\hline $\begin{array}{l}\text { Crown } \\
\text { Cresta } \\
\text { Chaser }\end{array}$ & $\begin{array}{l}\text { 1G-EU } \\
\text { lG-EU, 1S-U } \\
\text { lG-EU }\end{array}$ & 9 & 7 & 16 \\
\hline Corona & 1S-LU, 1S-iLU, 3A-LU & 9 & 9 & 18 \\
\hline $\begin{array}{l}\text { Carina } \\
\text { Camry } \\
\text { Vista }\end{array}$ & $\begin{array}{l}\text { 3A-LU, 3A-U } \\
\text { 1S-LU, } \\
\text { 1S-iLU }\end{array}$ & 10 & 9 & 19 \\
\hline $\begin{array}{l}\text { Corolla } \\
\text { Gorolla II }\end{array}$ & $\begin{array}{l}\text { 2A-LU, 3A-U, 3A-LU } \\
2 \mathrm{~A}-\mathrm{LU}, 3 \mathrm{~A}-\mathrm{U}\end{array}$ & 11 & 11 & 22 \\
\hline Starlet & $4 \mathrm{~K}-\mathrm{U}$ & 7 & 8 & 15 \\
\hline $\begin{array}{l}\text { Galant } \Sigma \\
\text { Chariot } \\
\text { Lancer Fiore } \\
\text { Lancer EX } \\
\text { Mirage }\end{array}$ & $\begin{array}{l}\text { G32B } \\
\text { G62B }(T) \\
\text { G15B } \\
\text { G12B } \\
\text { G12B }(T)\end{array}$ & 8 & 7 & 15 \\
\hline $\begin{array}{l}\text { Capella } \\
\text { Familia }\end{array}$ & $\begin{array}{l}\text { F8 } \\
\text { E5, E5(E), E5(ET) }\end{array}$ & 12 & 10 & 22 \\
\hline
\end{tabular}


き車の比率が $40 \%$ を越えたことや，ミッドシップカーの出現 等もあり, これらの変化を踏まえたオクタン価要求值の動向を 把握する目的で調査を実施した。

本報告は, 本年度試験車 12 車種 111 台を選定し, 石油学会 規格 JPI-6S-6-84 オクタン価要求值測定法基準に従い試験を 実施した。以下にその結果を報告する。

\section{2. 試 験 車}

試験車として 1984 年型の新型車または新造車の中から比較 的登録台数比率の高い12 車種 111 台を選定した。このうち自 動変速機付き車 46 台, ターボチャージャ付き車 7 台が含まれて いる。なお, 試験車の調達に際しては ORI（オクタン価要求 值増加）などを考虑してカーボン落とし後の走行距離が 6,000 $\mathrm{km}$ 以上の車を選定した。

本年度のデータ 集計は, 石油学会規格 JPI-6S-7-84 オク タン価要求值分布推定法基準を用い, 本年度試験車 111 台に 1983 年度試験車のうち 仕様変更なく, 引続き販売されている 車で本年度の対象車種になっている 12 車種 97 台の結果を加 壳た合計 12 車種 208 台（うち自動変速機付き車 87 台 41.8
$\%$ ，ターボチャージャ付き車 9 台 4.3\%) の試験結果を統計的 にまとめたものである。これらの試験車の車種名, エンジン型 式を Table 1 に示す。

\section{3. 標 準 燃 料}

3.1 正標準燃料 (Primary Reference Fuel : PRF) イソオクタンと $n$-ヘプタンの混合により調製した。

\section{$3 \cdot 2$ 全沸点型標準燃料}

全沸点型標準燃料として混合系標準燃料を用いた。この標準 然料の調製は Table 2 に従って行った。また, 調製に用いた それぞれの基油の一般性状を Table 3 に示す。

\section{4. 試 験方法}

試験は石油学会規格 JPI-6S-6-84 に従い行った。なお，加 速条件は Table 4 に示す条件で行った。

\section{5. 試 験場 所}

試験は主として参加機関の 保有するシャシーダイナモメー ターを用い, 一部を日本自動車研究所のテストコースで実施

Table 2 Full Boiling Range Reference Fuel

\begin{tabular}{|c|c|c|c|c|}
\hline \multirow{2}{*}{ Type } & \multirow{2}{*}{$\begin{array}{l}\text { Range of Octane } \\
\text { Number }\end{array}$} & \multicolumn{3}{|c|}{ Blending Stocks } \\
\hline & & High Octane Number & Low Octane Number & Supplemental \\
\hline \multirow{2}{*}{ Mixed Type } & $70 \sim 94$ & \multirow{2}{*}{$\begin{array}{c}\text { Mixture of } 60 \% \text {, Reformate } \\
\text { and } 40 \% \\
\text { Cracked Naphtha }\end{array}$} & Straight-Run Naphtha & - \\
\hline & $95 \sim 100$ & & $\longrightarrow$ & Toluene \\
\hline
\end{tabular}

Table 3 The Properties of Blending Stocks

\begin{tabular}{|c|c|c|c|c|}
\hline Test Item & Cracked Naphtha & Reformate Naphtha & L. St. Naphtha & Toluene \\
\hline $\begin{array}{l}\text { Sq. Gr., } 15 / 4^{\circ} \mathrm{C} \\
\text { R. V.P., } \mathrm{kg} / \mathrm{cm}^{2} @ 37.8 \\
\text { Distillation (\% evaporated) }\end{array}$ & $\begin{array}{l}0.7295 \\
0.625\end{array}$ & $\begin{array}{l}0.7330 \\
0.540\end{array}$ & $\begin{array}{l}0.6686 \\
0.770\end{array}$ & $\begin{array}{l}0.8720 \\
0.100\end{array}$ \\
\hline I. B. P., $\quad{ }^{\circ} \mathrm{G}$ & 32.5 & 37.0 & 34.0 & $110.2 *$ \\
\hline $10 \%$ & 50.0 & 59.0 & 45.5 & 110.4 \\
\hline $50 \%$ & 91.0 & 107.5 & 58.5 & 110.5 \\
\hline $90 \%$ & 165.0 & 144.0 & 90.0 & 110.5 \\
\hline $95 \%$ & 178.5 & 153.0 & 98.0 & 110.6 \\
\hline E. P. & 193.0 & 169.0 & 114.0 & 110.7 (D.P.) \\
\hline Recovery, vol. \% & 98.5 & 98.0 & 98.0 & 99.0 \\
\hline $\begin{array}{l}\text { Residue, vol. \% } \\
\text { FIA Analysis : }\end{array}$ & 1.0 & 1.0 & 1.0 & 0.5 \\
\hline Saturate, vol. \% & 45.7 & 50.0 & 98.0 & \\
\hline Olefin, vol. $\%$ & 37.4 & 0.0 & 0.0 & \\
\hline Aromatic, vol. $\%$ & 16.9 & 50.0 & 2.0 & \\
\hline Octane No. Research Method & 92.5 & 95.7 & 63.7 & \\
\hline Motor Method & 79.7 & 86.8 & 62.8 & \\
\hline
\end{tabular}

* BTX Method

Table 4 Acceleration Method

\begin{tabular}{c|c|c|l}
\hline Acceleration Method & Type of Transmission & Initial Speed at Acceleration & \multicolumn{1}{|c}{ Throttle Condition } \\
\hline \multirow{4}{*}{ Low Speed Acceleration } & Manual & $1,000 \mathrm{rpm}$ & Wide Open Throttle (WOT) \\
\cline { 2 - 4 } & Automatic & $30 \mathrm{~km} / \mathrm{hr}$ & Part Throttle (PT) \\
\cline { 2 - 4 } & & & Detent Acceleration \\
\hline
\end{tabular}


Table 5 Octane Number Requirement Distribution (WOT)

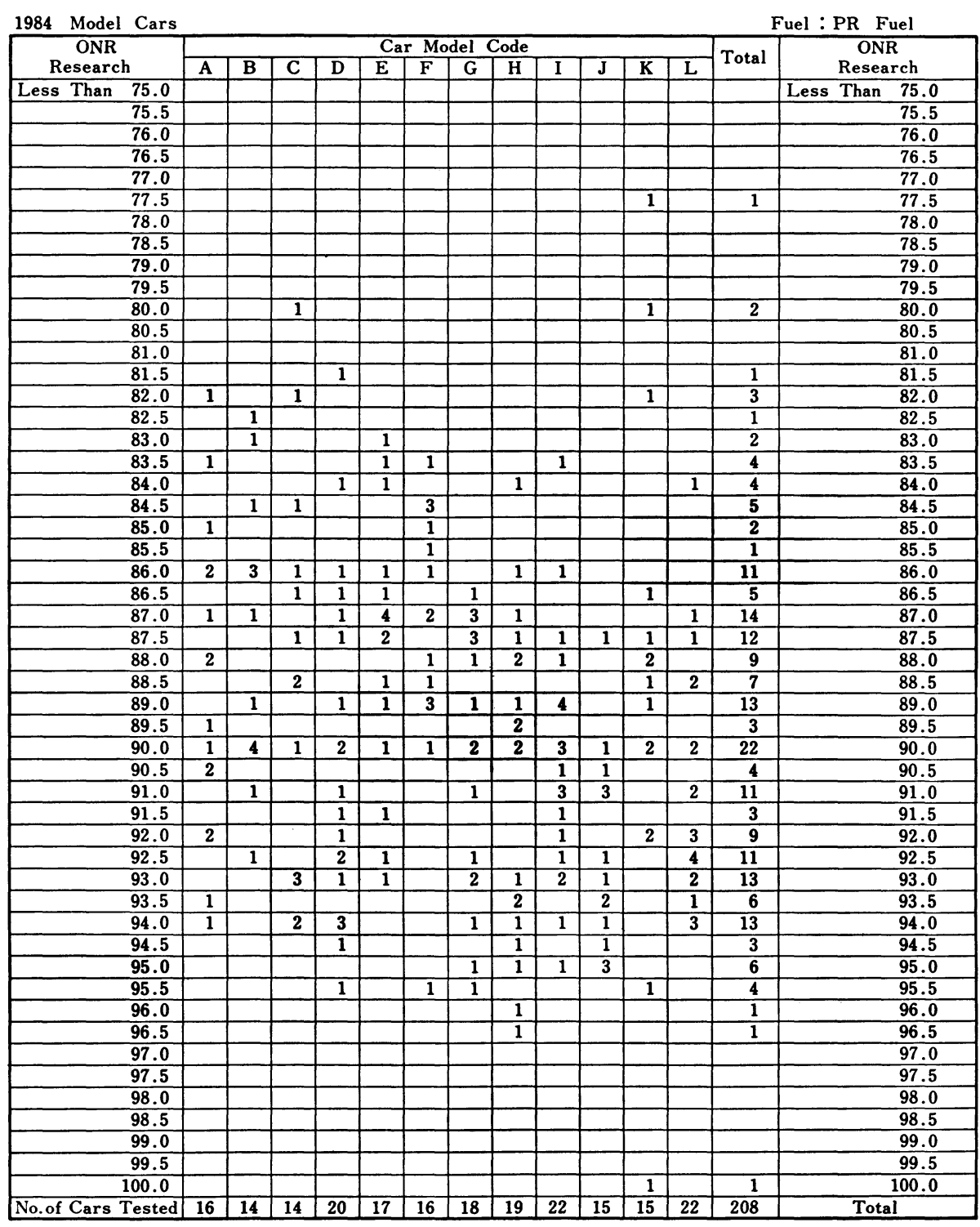

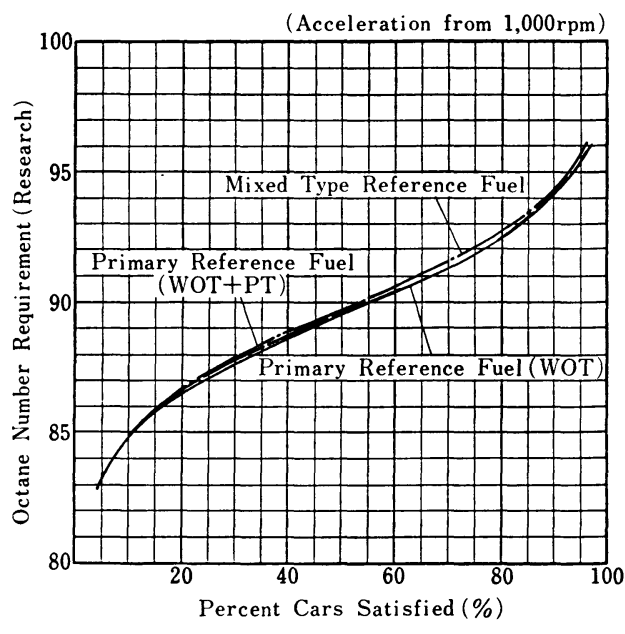

Fig. 1 Octane Number Requirement Distribution of 1984 Model Cars
した。

\section{6. 試験結果および考察}

\subsection{4 年型全車のオクタン価要求値分布}

1984 年型全車のオクタン価要求值分布は, 本年度試験車 111 台に 1983 年度試験車のらち 12 車種 97 台を加えた 12 車種 208 台の結果をもとに, 石油学会規格の解析方法の計算式によ って求めた。なお，正標準燃料および混合系標準然料の絞り弁 全開加速条件での車種別オクタン価要求值測定結果をそれぞれ

Tables 5, 6 に示す。

1984 年型全車の低速法オクタン価要求值分布を Fig. 1 に 示す。この図より求めた 1984 年型全車の 10,50 および $90 \%$ 充足率におけるオクタン価要求值分布を Table 7 に示す。

正標準燃料絞り弁全開加速条件でのオクタン価要求值分布を 1983 年型全車と比較し, Fig. 2 に示す。

この図が示すよらに 1984 年型全車は, 1983 年型全車に比べ 
Table 6 Octane Number Requirement Distribution (WOT)

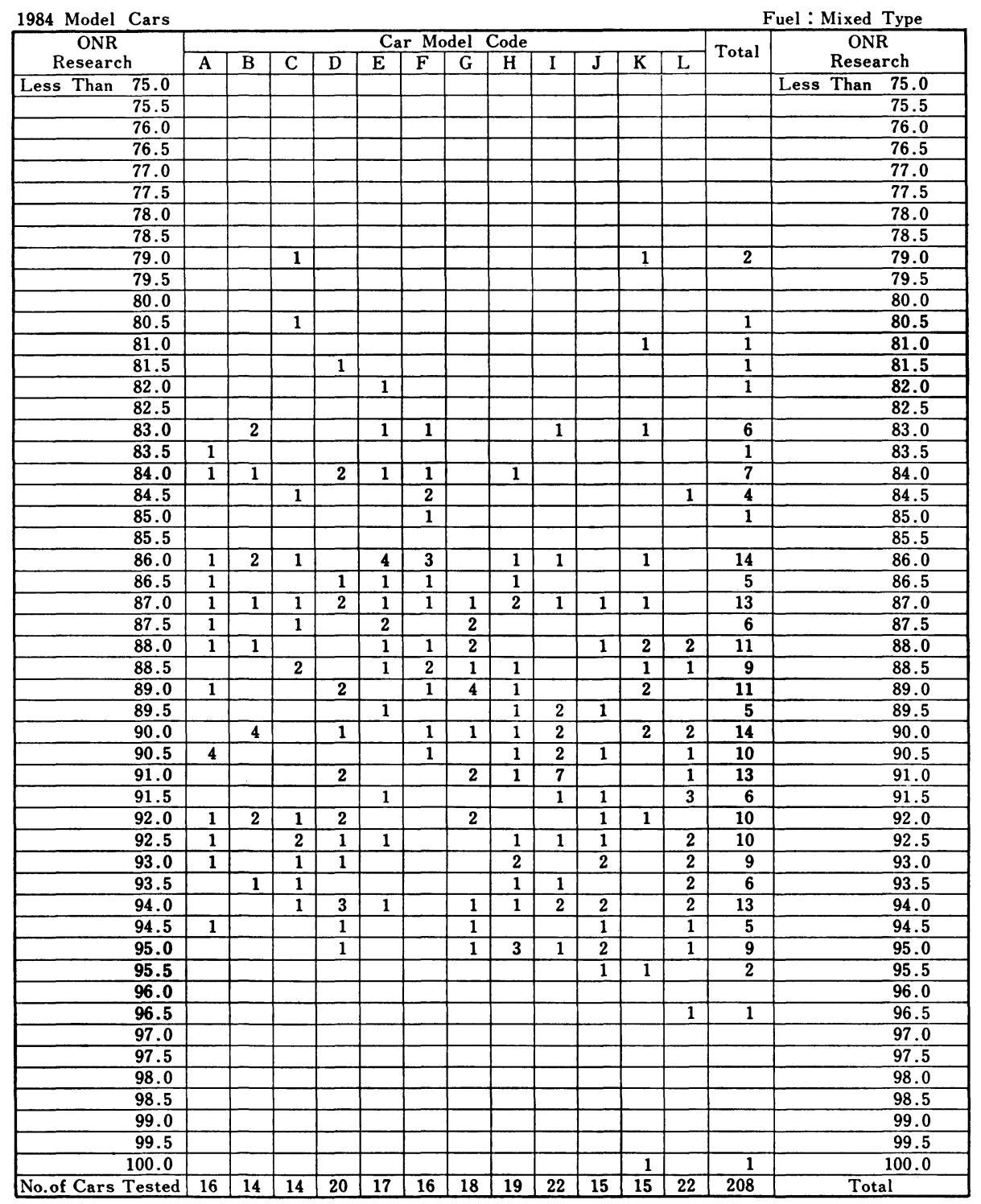

Table 7 Octan Number Requirement of 1984 Model Cars (Research Method)

\begin{tabular}{c|ccc}
\hline \multirow{3}{*}{ Reference Fuel } & \multicolumn{3}{l}{ Test Method and Throttle Condition } \\
\cline { 2 - 4 } & \multicolumn{3}{l}{$\begin{array}{l}\text { Low Speed Acceleration, Wide Open } \\
\text { Throttle }\end{array}$} \\
\cline { 2 - 4 } & \multicolumn{3}{|c}{ Cars Satisfied \% } \\
\cline { 2 - 4 } & 10 & 50 & 90 \\
\hline Primary Reference & 84.8 & 89.6 & 94.1 \\
Fuel Mixed Type & 84.8 & 89.8 & 94.2 \\
\hline
\end{tabular}

10\% 充足率では高い值を示したが，50 および 90\% 充足率で 低い值を示した。

また，最近 5 年間の年型全車における低速法オクタン価要求 值分布の推移を Fig. 3 および Table 8 に示す。この結果か ら $50 \%$ 充足率においては大きな変化はないが，10\% 充足率で は増加傾向を示し， 90\% 充足率では減少傾向を示した。

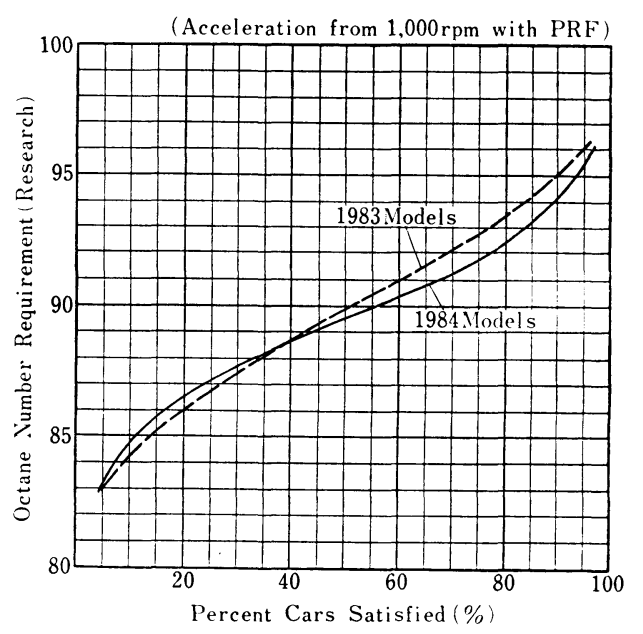

Fig. 2 Octane Number Requirement Distribution, Comparison between 1983 Model Cars and 1984 Model Cars 


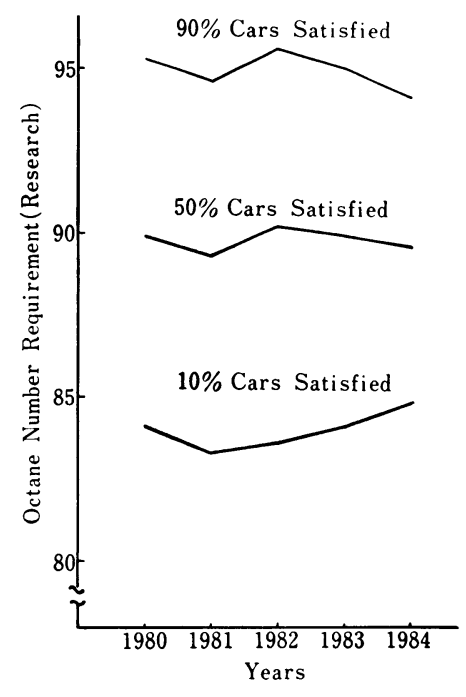

Fig. 3 Trends of Octane Number Requirement

\section{$6 \cdot 2$ 排気量別オクタン価要求值分布}

1984 年度試験車の排気量を 3 区分 $(1,300 \mathrm{cc}$ 以下, 1,301 $1,600 \mathrm{cc}$ および $1,601 \sim 2,000 \mathrm{cc})$ にして求めた排気量別オク タン価要求值分布の 10,50 および $90 \%$ 充足率におけるオク タン価要求值分布を Table 9 に示す。この結果から排気量別 の低速法オクタン価要求值分布は各標準然料とも，10および $50 \%$ 充足率において $1,300 \mathrm{cc}$ 以下の区分が最も高い值を示し た。

\section{3 各標準然料間の差}

1984 年型全車の 各標準燃料の差を Fig. 1 からみると混合
Table 8 Octane Number Requirement of 1980 1984 Model Cars on PRF (Research Method)

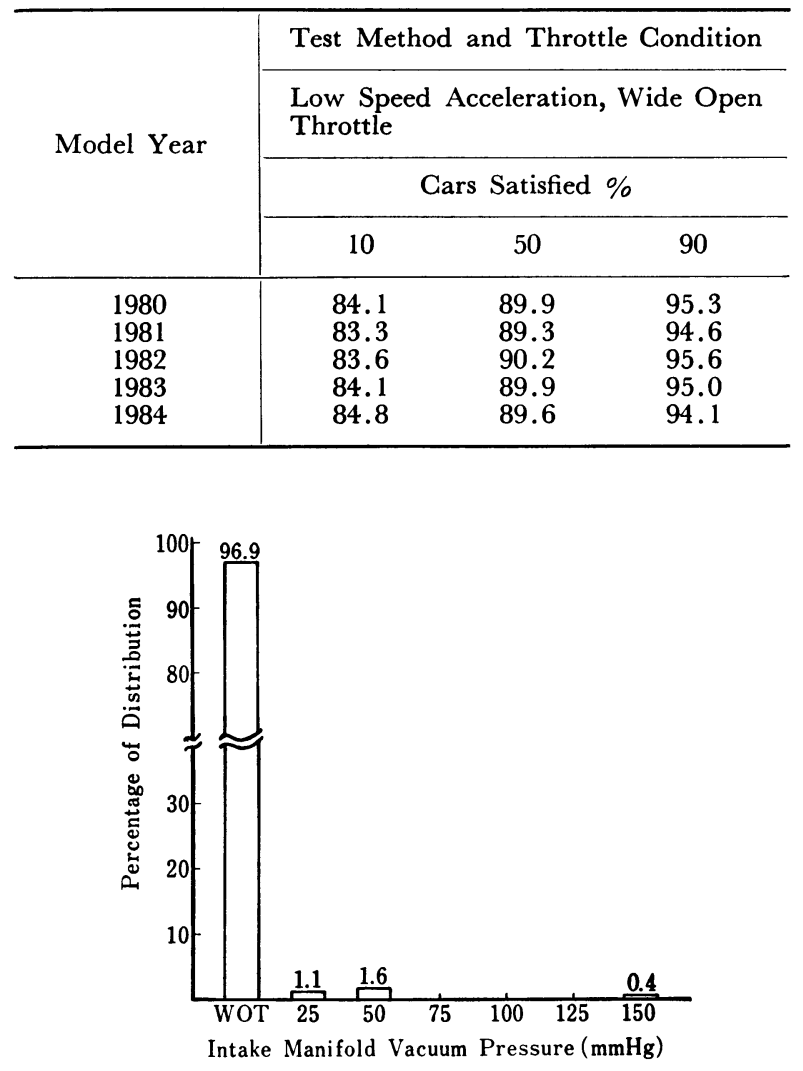

Fig. 4 Distribution of Intake Manifold Vacuum Pressure of Maximum ONR with PRF

Table 9 Octane Number Requirement with Engine Displacement (Research Method)

Test Method : Low Speed Acceleration

\begin{tabular}{|c|c|c|c|c|c|c|}
\hline \multirow{3}{*}{ Engine Displacement } & \multicolumn{6}{|c|}{ Reference Fuels } \\
\hline & \multicolumn{3}{|c|}{ Primary Reference Fuel } & \multicolumn{3}{|c|}{ Mixed Type } \\
\hline & \multicolumn{6}{|c|}{ Cars Satisfied \% } \\
\hline cc & 10 & 50 & 90 & 10 & 50 & 90 \\
\hline $\begin{array}{c}1,601 \sim 2,000 \\
1,301 \sim 1,600 \\
\text { Smaller than } 1,300\end{array}$ & $\begin{array}{l}83.8 \\
84.3 \\
86.6\end{array}$ & $\begin{array}{l}88.7 \\
89.6 \\
90.5\end{array}$ & $\begin{array}{l}93.6 \\
94.8 \\
94.3\end{array}$ & $\begin{array}{l}84.2 \\
84.3 \\
86.5\end{array}$ & $\begin{array}{l}89.0 \\
89.5 \\
90.5\end{array}$ & $\begin{array}{l}93.7 \\
94.7 \\
94.7\end{array}$ \\
\hline
\end{tabular}

Table 10 Trend of Engine Speeds for Maximum Octane Number Requirements under WOT Acceleration Condition (Percentage of Test Cars)

\begin{tabular}{|c|c|c|c|c|c|c|c|c|}
\hline \multirow{4}{*}{ Model Year } & \multicolumn{8}{|c|}{ Engine Speeds (rpm) } \\
\hline & \multicolumn{2}{|c|}{1,000} & \multicolumn{2}{|c|}{$1,050 \sim 2,000$} & \multicolumn{2}{|c|}{$2,050 \sim 3,000$} & \multicolumn{2}{|c|}{ More than 3,050} \\
\hline & \multicolumn{8}{|c|}{ Reference Fuels } \\
\hline & PRF & Mixed Type & PRF & Mixed Type & PRF & Mixed Type & PRF & Mixed Type \\
\hline $\begin{array}{l}1980 \\
1981 \\
1982 \\
1983 \\
1984\end{array}$ & $\begin{array}{r}14.0 \\
9.0 \\
7.6 \\
12.2 \\
13.9\end{array}$ & $\begin{array}{l}15.6 \\
11.9 \\
11.0 \\
10.6 \\
13.1\end{array}$ & $\begin{array}{l}48.2 \\
51.4 \\
54.0 \\
51.9 \\
42.1\end{array}$ & $\begin{array}{l}46.7 \\
44.9 \\
47.9 \\
49.7 \\
39.8\end{array}$ & $\begin{array}{l}30.2 \\
21.9 \\
26.0 \\
26.3 \\
38.1\end{array}$ & $\begin{array}{l}27.3 \\
22.5 \\
25.2 \\
27.6 \\
39.2\end{array}$ & $\begin{array}{r}7.6 \\
17.7 \\
12.4 \\
9.6 \\
5.9\end{array}$ & $\begin{array}{r}10.4 \\
20.7 \\
15.9 \\
12.1 \\
7.9\end{array}$ \\
\hline
\end{tabular}




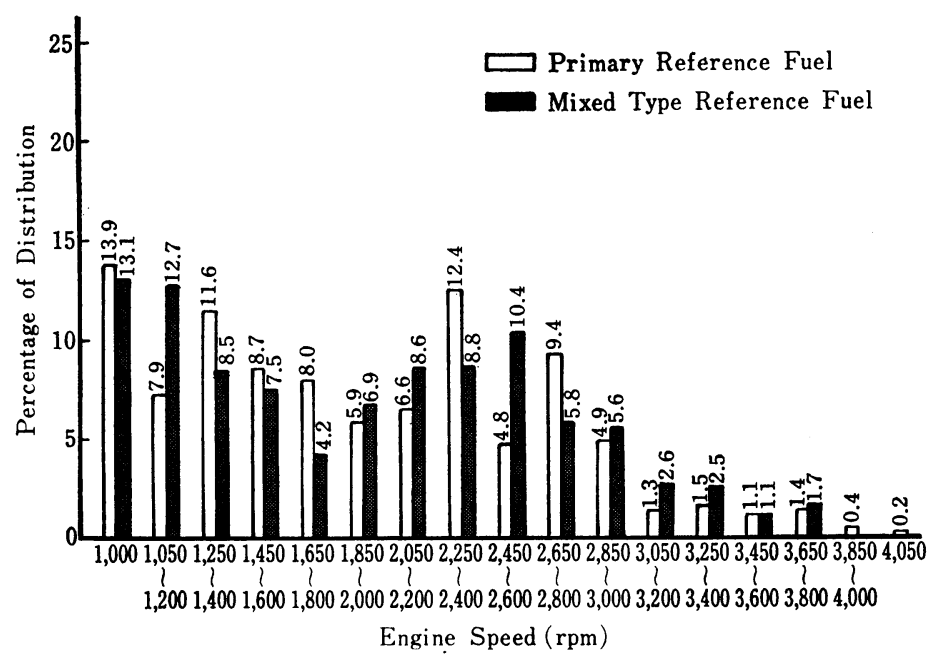

Fig. 5 Distribution of Engine Speed of Maximum ONR under WOT Acceleration Condition

系標準燃料は正標準燃料とほぼ同等であった。

\section{4 オクタン価要求値最高を示す吸入マニホールド負圧分} 布

1984 年型全車のオクタン価要求值最高を示す吸入マニホー ルド負圧分布を Fig. 4 に示す。この図から吸入マニホールド 負圧分布は絞り弁全開加速で $96.9 \%$ と最も多く, 残り $3.1 \%$ は 25 150 mmHg の範囲に分布している。

\section{5 オクタン価要求值最高を示す速度分布}

1984 年型全車の絞り弁全開加速に打けるオクタン価要求值 最高を示す速度分布を各標準然料別に Fig. 5 に示す。この図 からオクタン価要求值最高を示すェンジン回転速度は広範囲に 分布している。Table 10 に示すその年次推移をみると, 1,050 〜2,000 rpm でオクタン価要求值最高を示す車が最も多いが, 1984 年度に拈いて $2,050 \sim 3,000 \mathrm{rpm}$ の範囲の 台数割合が増 加してきているのが注目される。

\section{7. 関係者（順不同）}

製品部会長 露木重彦(東亜燃料工業)

ガソリン分科会委員長 保坂弘毅(東亚燃料工業)

オクタン価要求值専門委員会(本調査には以下の 19 機関が 参加した）

主查 大道勝利(出光興産)

幹事 熊倉昭夫(アジア石油), 大平博文 (エッソ石油), 長谷 川 豊 (東亜然料工業), 玉之内光男 (日本鉱業), 野崎 信義(日本石油)

委員吉村 隆(鹿島石油), 仏常正美 (キグナス石油), 山崎 英敏 (共同石油), 松田正二(興覀石油), 岡見克次 (昭 和シェル石油), 長嶋一俊 (昭和シェル石油), 馬場征 夫 (ゼネラル石油), 三木直光 (大協石油), 芳賀 勝 (日 本石油精製), 山崎 明 (日網石油精製), 三瀬一好 (丸善 石油), 若井 隆 (三菱石油), 花田政光 (モービル石油) 


\section{Octane Number Requirement Survey of 1984 Japanese Passenger Cars}

The Sub-Committee of Octane Number Requirement Survey, Gasoline Section, Products Division of The Japan Petroleum Institute

The Sub-Committee of Octane Number Requirements (ONR) of the Japan Petroleum Institute has made a 1984 ONR survey on 111 Japanese passenger cars, including 46 cars having automatic transmissions of 12 different models.

The minimum mileage required to stabilize ONR has been increased to $6,000 \mathrm{~km}$.

Test vehicles and engine types are shown in Table 1.

Primary Reference Fuel (PRF) and mixed types of unleaded Full Boiling Range Reference Fuel (FBRRF) have been used as reference fuels.

The blending proportions for preparing the FBRRF and properties of the blending stocks are shown in Tables 2 and 3, respectively.

The low speed method test was mainly carried out on the ten chassis dynamometers belonging to the participant companies and partly at the test track of the Japan Automobile Research Institute.

The simulated road load of the chassis dynamometers was set arbitrarily by each participant but the inertia weight of the chassis dynamometer was set near the gross weight of each vehicle.

The determination of knock was performed according to the JPI Standard Method 6S-6-84.

The low-speed method knock was identified in engine speed range from $1,000 \mathrm{rpm}$ to $4,000 \mathrm{rpm}$ during acceleration at the highest gear position.

The test results obtained were treated statistically in accordance with JPI Standard Method 6S-7-84, in order to calculate the car satisfaction distribution for each of the given octane number.

For these statistical data, ONRs of 97 cars surveyed in 1983 were incorporated in the calculations, since there are 1984 model year cars which are similar to the 1983 model year cars which have been already tested.

These results are shown in Table 7 and illustrated in Fig. 1.

The low speed ONRs of 1984 model cars for $50 \%$ and $90 \%$ market satisfaction with the PRF were 89.6 and 94.1 octane numbers, respectively.

The ONR distributions of 1984 model cars are summarized in Tables 5 and 6.

\section{Keywords}

Committee report, Japanese passenger car, Octane number requirement 